\title{
Microplastic-Associated Biofilms: A Comparison of Freshwater and Marine Environments
}

\author{
Jesse P. Harrison, Timothy J. Hoellein, Melanie Sapp, Alexander S. Tagg, \\ Yon Ju-Nam, and Jesús J. Ojeda
}

\begin{abstract}
Microplastics ( $<5 \mathrm{~mm}$ particles) occur within both engineered and natural freshwater ecosystems, including wastewater treatment plants, lakes, rivers, and estuaries. While a significant proportion of microplastic pollution is likely sequestered within freshwater environments, these habitats also constitute an important conduit of microscopic polymer particles to oceans worldwide. The quantity of aquatic microplastic waste is predicted to dramatically increase over the next decade, but the fate and biological implications of this pollution are still poorly understood. A growing body of research has aimed to characterize the formation, composition, and spatiotemporal distribution of microplastic-associated ("plastisphere") microbial biofilms. Plastisphere microorganisms have been suggested to play significant roles in pathogen transfer, modulation of particle buoyancy, and biodegradation of plastic polymers and co-contaminants, yet investigation of these topics within freshwater environments is at a very early stage. Here, what is known about marine plastisphere assemblages is systematically compared with up-to-date findings from freshwater habitats. Through analysis of key differences and likely commonalities between environments, we discuss how
\end{abstract}

\footnotetext{
J.P. Harrison $(\bowtie)$

Division of Microbial Ecology, Department of Microbiology and Ecosystem Science,

Research Network "Chemistry Meets Microbiology”, University of Vienna, Vienna A-1090,

Austria

e-mail: jesse.p.harrison@gmail.com

T.J. Hoellein

Department of Biology, Loyola University Chicago, Chicago, IL 60660, USA

M. Sapp

Institute of Population Genetics, Heinrich Heine University Düsseldorf, Düsseldorf 40225, Germany
}

A.S. Tagg, Y. Ju-Nam, and J.J. Ojeda

Systems and Process Engineering Centre, College of Engineering, Swansea University, Swansea SA1 8EN, UK 
an integrated view of these fields of research will enhance our knowledge of the complex behavior and ecological impacts of microplastic pollutants.

Keywords Biodegradation, Biofilms, Microorganisms, Pathogens, Plastisphere

$\begin{array}{ll}\text { Abbreviations } & \\ \text { BONCAT } & \text { Bioorthogonal noncanonical amino acid tagging } \\ \text { FACS } & \text { Fluorescence-activated cell sorting } \\ \text { FISH } & \text { Fluorescence in situ hybridization } \\ \text { FT-IR } & \text { Fourier-transform infrared } \\ \text { HDPE } & \text { High-density polyethylene } \\ \text { LDPE } & \text { Low-density polyethylene } \\ \text { MALDI-ToF MS } & \text { Matrix-assisted laser desorption/ionization time-of-flight mass } \\ & \text { spectrometry } \\ \text { MDA } & \text { Multiple displacement amplification } \\ \text { PET } & \text { Polyethylene terephthalate } \\ \text { PHBV } & \text { Polyhydroxybutyrate-polyhydroxyvalerate } \\ \text { PP } & \text { Polypropylene } \\ \text { PS } & \text { Polystyrene } \\ \text { (r)DNA } & \text { (Ribosomal) deoxyribonucleic acid } \\ \text { (r)RNA } & \text { (Ribosomal) ribonucleic acid } \\ \text { SIMS } & \text { Secondary ion mass spectrometry } \\ \text { SNP } & \text { Single-nucleotide polymorphism } \\ \text { UV } & \text { Ultraviolet } \\ \text { WWTP } & \text { Wastewater treatment plant } \\ \text { XPS } & \text { X-ray photoelectron spectroscopy } \\ \text { XRD } & \text { X-ray diffraction }\end{array}$

\section{Introduction}

Microplastics (particles with an upper size limit of $<5 \mathrm{~mm}$ ) are globally distributed within aquatic environments, with up to 51 trillion pieces estimated to float at sea alone $[1,2]$. They are encountered within the water column and sediments, with the latter functioning as a sink for the accumulation of plastic waste [3-5]. Most plastic litter originates from land-based activities, with wastewater treatment plant (WWTP) and inland waters comprising an important route through which this pollution reaches marine environments $[6,7]$. While a substantial proportion of microplastic is likely to become sequestered within freshwaters, the amount of plastic entering the sea is predicted to increase by an order of magnitude by 2025 (corresponding to an input of up to 250 million metric tons) [7]. Legislation for phasing out microplastics in cosmetic products (e.g., the Microbead-Free Waters Act of 2015 in the USA) can be expected to achieve only a limited reduction in the quantity of environmental plastic debris. 
A growing body of research has investigated the impacts of microplastics on biota, which may involve direct and indirect processes (e.g., physical blockage caused by ingested particles, as well as their ability to transport harmful compounds, pathogens, and algae) [2, 8-10]. Even so, little is known about the ecological effects of microplastics within freshwaters [10]. For example, while microplastic-associated microbial (bacterial, archaeal, and picoeukaryotic) assemblages are likely to profoundly influence the distribution, impacts, and fate of these pollutants, research into this topic has focused on marine environments [11-13]. In streams and other habitats, biofilms ${ }^{1}$ are primary sites for carbon and nutrient transformations and form the base of food webs, contributing to local and global ecosystem functioning [14]. As they are also essential to pollutant biodegradation, an improved knowledge of microbial-microplastic interactions is required to predict the environmental impacts of plastic debris [15]. Investigating this topic could inform the development of solutions to manage plastic pollution by determining how it affects processes including microbially mediated primary production and interactions between plastic-associated ("plastisphere") taxa and other organisms $[11,12,16,17]$. It could also lead to insights concerning the biodegradability of plastic litter and facilitate the development of new approaches to plastic disposal and/or recycling [18].

Freshwater and marine habitats share a number of features, but there are also differences between them that may affect the development and activities of plastisphere consortia. To facilitate investigation of this topic, findings based on marine plastisphere research are compared with those available for freshwaters. Following an assessment of recent discoveries concerning the formation and distribution of plastic-associated biofilms, our knowledge concerning their ecological roles and ability to drive processes including polymer biodegradation is considered. Finally, some of the main knowledge gaps in plastisphere research are discussed and used to highlight methodological advances in microbial ecology that could be used to improve our understanding of microbial-microplastic interactions.

\section{Freshwater Plastisphere Assemblages: State of the Science}

\subsection{Factors Contributing to Biofilm Formation and Composition}

Fundamental processes involved in biofilm formation are well established, with initial attachment followed by maturation and the eventual detachment of cells [19]. There are also further factors that may influence the formation, composition,

\footnotetext{
${ }^{1}$ Surface-associated aggregates of microbial cells encased in a matrix of extracellular polymeric substances.
} 
Factors driving biofilm formation and composition on plastic

\begin{tabular}{|c|c|}
\hline $\begin{array}{c}\text { Surface } \\
\text { chemistry } \\
\text { and structure }\end{array}$ & $\begin{array}{l}\text { Polymer type } \\
\text { Adsorbed and leaching chemicals } \\
\text { Age / weathering } \\
\text { Particle size }\end{array}$ \\
\hline $\begin{array}{l}\text { Biological } \\
\text { interactions }\end{array}$ & $\begin{array}{l}\text { Pioneer colonizers } \\
\text { Successional stage } \\
\text { Competition } \\
\text { Grazing / ingestion }\end{array}$ \\
\hline $\begin{array}{l}\text { Local } \\
\text { environmental } \\
\text { conditions } \\
\text { (incl. } \\
\text { seasonal } \\
\text { fluctuations) }\end{array}$ & $\begin{array}{l}\text { Temperature } \\
\text { Oxygen } \\
\text { Nutrients } \\
\text { Light } \\
\text { Salinity } \\
\text { Pressure } \\
\text { Presence of other pollutants }\end{array}$ \\
\hline $\begin{array}{l}\text { Movement } \\
\text { and transport } \\
\text { between } \\
\text { habitats }\end{array}$ & $\begin{array}{l}\text { Buoyancy } \\
\text { Flocculation } \\
\text { Particle spiraling } \\
\text { Flooding } \\
\text { Currents }\end{array}$ \\
\hline Biogeography & Geographic location \\
\hline
\end{tabular}

Fig. 1 Physical, chemical, and biological factors likely to affect the formation and composition of plastisphere microbial assemblages. Only a limited selection of these parameters has been investigated with specific reference to microplastics

and activities of plastic-associated biofilms (Fig. 1). Only some of the parameters shown in Fig. 1 have been investigated with reference to microplastics. However, efforts to identify factors driving the formation of these assemblages in marine habitats have recently been reviewed $[12,13,20]$.

Microplastics are rapidly colonized by environmental microorganisms (within hours; [21]). Many factors driving the development of plastisphere communities are likely to be similar between freshwater and marine habitats. For example, in agreement with research into biofilm formation on other artificial substrata $[19,22]$, there is evidence for the importance of surface properties (including roughness and hydrophobicity) during early colonization of microplastics $[12,23]$. Exposure to ultraviolet (UV) radiation and waves can modify the surface chemistry and structure of plastics (e.g., via the formation of cracks and pits, a reduction in molecular weight, and an increase in surface oxidation), which may 
facilitate biofilm formation [24, 25]. Plastic-colonizing microorganisms have also been found to influence the surface properties and buoyancy of polymers [12, 20, 26]. Since microplastics are likely to be transported into marine environments via WWTP, rivers, and streams [6, 7], factors contributing to initial colonization (such as surface roughness and attachment by pioneering colonizers) can be hypothesized to be particularly important within freshwaters. The impacts of particle age and/or weathering on plastisphere consortia may be comparatively pronounced within marine ecosystems where the residence times of plastic often exceed those within rivers and streams [24]. However, microplastics additionally accumulate within environments such as lakes, where they may persist for decades (similar to timescales predicted for marine habitats) and can be exposed to high levels of UV radiation $[2,27,28]$. Local-scale differences in the composition of plastisphere assemblages between polymer types have been found [12, 29, 30], but it is unknown whether there are any general differences in the dominant types of plastic within freshwater and marine ecosystems. Moreover, although it is possible that the ingestion of plastics by higher organisms could have an impact on plastisphere colonization processes, this topic has not been investigated [11, 20, 30].

Ambient conditions such as temperature, salinity, pressure, and the availabilities of light and oxygen are likely to influence the development of plastic-associated biofilms (Fig. 1) [29, 31]. Many of these conditions differ between freshwater and marine ecosystems, and WWTP and unmanaged freshwaters. For example, the low temperatures $\left(<5^{\circ} \mathrm{C}\right)$, absence of light, and elevated pressure within deep waters are likely to impose selective forces on plastisphere assemblages that differ from those within shallow habitats. In contrast with the frequently nutrient-poor conditions present within the open ocean, inland and coastal waters receive high fluxes of nutrients from the surrounding environment [14]. In addition to contributions from organic matter input and upwelling, high concentrations of nutrients (e.g., nitrogen and phosphorus) are released by agriculture and other human activities. Many plastisphere members have been affiliated with pollutant degradation $[12,13,20$, $21]$, and it is probable that several contaminants play a role in shaping biofilm formation and activities on polymers (Fig. 1). Indeed, multiple types of pollutants, as well as heavy metals, are known to become adsorbed onto microplastics [2, 8 , 10].

Further to these factors, physical processes contributing to the movement of suspended particles differ between freshwater and marine habitats [2]. Continuous downstream movement of water is a key distinction between freshwater and marine ecosystems. In rivers, sediment movement is characterized using the concept of "spiraling" $[32,33]$. The components of one spiral include downstream transport, deposition, bed load transport, and resuspension. This concept is a well-developed approach for modeling particle movement and is quantified using measurements of deposition length and velocity, turnover time, and the retention-export ratio [34]. To date, direct measurements of spiraling metrics have not been applied to microplastic (but see Kowalski et al. [26], Long et al. [35], and Nizzetto et al. [36]). 
Each step in a spiral is likely to have implications for plastic-associated biofilm composition and activity, due to accompanying shifts in the surrounding environmental conditions (Fig. 1) [29, 31]. Studies of microplastic spiraling metrics will help estimate the spatial scales over which plastic particles move within lotic environments, informing how the associated microbial communities can be expected to change across multiple downstream spirals. Rivers are also characterized by flooding, which redistributes materials between riparian and aquatic components of the fluvial landscape $[37,38]$. Flooding moves plastic from the riparian zone into aquatic habitats and increases stranding of plastic in debris dams [39]. Analogous processes in marine environments include tidal movements and storm surges which strand plastic on intertidal or wrack zones [2]. Despite their likely impacts on plastisphere communities (Fig. 1), the effects of movement between aquatic and terrestrial habitats on plastic-associated biofilms have not been studied.

Hydrology in most lakes includes at least a single upstream inlet and downstream outlet, with water and particle residence times depending on water volume and currents. Little is known about plastisphere communities in lakes (Sect. 2.2), but research into this topic can be expected to benefit from a budgetary approach which measures rates of microplastic inflow, outflow, and retention. These metrics will determine microplastic residence times, which are likely to influence microbial-plastic associations within several habitats, including the epilimnion, littoral, and benthic zones (Sect. 3.1). Wind and wave action are likely to further influence the distribution of microplastics within lakes [2].

It is unclear how transport of microplastics from freshwater to marine environments affects plastisphere assemblages, but they may undergo a variety of taxonomic and physiological shifts during this transition (Sects. 2.2 and 2.3) [20, 40]. For example, subjecting Pseudomonas aeruginosa to salt stress $(0.5 \mathrm{M}$ $\mathrm{NaCl}$ ) was found to inhibit biofilm formation and reduce rates of benzoate degradation by this strain [41]. Geographic and seasonal differences in the structure and composition of freshwater plastisphere communities are yet to be investigated. However, the spatiotemporal distribution of marine plastic-colonizing microbial consortia has recently been studied [29, 30, 42]. Based on 6-week in situ exposures of polyethylene terephthalate (PET) bottles in the North Sea, Oberbeckmann et al. $[29,42]$ found location-dependent and seasonal differences in the structure and composition of plastisphere communities. Similar differences were also reported by Amaral-Zettler et al. [30]. Further to distinct communities being discovered in the North Atlantic and North Pacific subtropical gyres, the authors reported latitudinal gradients in the species richness of plastic-colonizing assemblages [30]. While taxonomic differences were also observed between polymer types, the data suggested that geography is likely to be a stronger predictor of plastisphere community composition at the scale of ocean basins [29, 30, 42]. 


\subsection{Examples of Microbial-Microplastic Interactions in Freshwater Habitats}

Despite measurements of plastic density and composition in freshwater ecosystems $[10,43]$, little is known about microbial associations with plastic in unmanaged freshwaters. A limited number of publications have investigated polymer biodegradation in lakes and rivers (Sect. 2.3), and there are at least three studies that have experimentally characterized the structure, composition, and/or activities of plasticassociated biofilms in these environments [44-46]. Because of differences in the study design and sites and the response parameters that were examined, there are few findings in common among these three studies. Thus, some of the major results of each study are discussed and compared with insights into marine microbialmicroplastic interactions.

Hoellein et al. [44] compared bacterial community composition and activity on six substrate types $(5 \times 5 \mathrm{~cm}$ pieces of ceramic tile, glass, aluminum, PET, leaf litter, and cardboard) in a river, a pond, and recirculating laboratory streams. In contrast with McCormick et al. [45] and several studies of marine plastisphere communities [21, 29, 47], the authors found no differences in the composition of plastic-colonizing biofilms relative to those on other solid substrates. The plastic, tile, and glass samples also showed similar rates of gross primary production and respiration. The primary factors for determining bacterial community composition and metabolic rates were the study site (river, pond, or artificial stream) and whether the substrate was hard (tile, glass, aluminum, and PET) or soft (leaf litter and cardboard). While the surface-colonizing assemblages on PET were compositionally similar to those on other surfaces, it was suggested that differences between substrate types may be stronger during early stages of biofilm formation. Similarly, Oberbeckmann et al. [42] found PET- and glass-colonizing communities to be compositionally similar following up to 6 weeks of exposure to seawater; the authors noted that higher-resolution studies may be required to distinguish "plastic-specific" taxa from other biofilm members. Taken together, these studies emphasize how investigating the early-stage development of plastisphere communities in more detail will be necessary not only in marine ecosystems [21] but also in freshwater habitats.

McCormick et al. [45] compared bacterial communities on microplastic, suspended organic matter (i.e., seston) and the water column downstream and upstream of a WWTP. All habitats differed from each other, and the microplastic community had a lower taxon diversity relative to seston and downstream water samples. In marine environments, plastic-associated microbial communities have also been found to be taxonomically distinct from those in the surrounding water [30, 47-49]. Genera selected for on plastic (relative to nonplastic habitats) in the study by McCormick et al. [45] included Pseudomonas, Arcobacter, Aeromonas, Zymophilus, and Aquabacterium. These genera contain species with the potential for plastic degradation and pathogenesis (Sect. 2.3). Aquabacterium commune is a common member of drinking water biofilms [50], and colonization of low-density 
Fig. 2 Scanning electron micrograph showing a biofilm attached to a HDPE fragment incubated in aerobic wastewater for 6 months. Microplastics are likely to function as vectors for the transport of microbial taxa from WWTP to other environments. The scale bar is $2 \mu \mathrm{m}$ (Credit: Alexander S. Tagg)

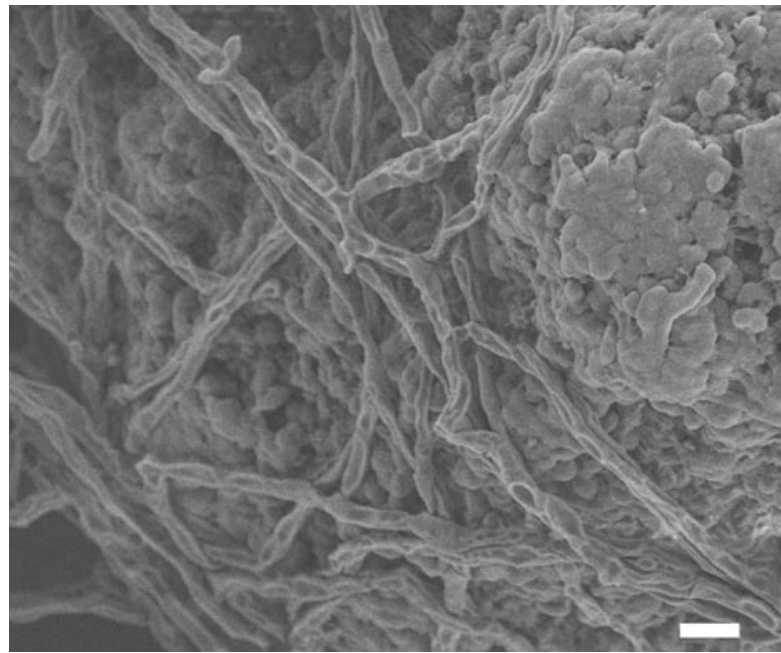

polyethylene (LDPE) by Arcobacter spp. has also been shown to occur in coastal marine sediments [21]. The study by McCormick et al. [45] was conducted immediately below a WWTP outfall, and it is unknown if wastewater-affiliated microbial communities will persist further downstream. However, the presence of plasticcolonizing Arcobacter spp. in both freshwater and marine habitats [21, 45] implies that certain genera could survive on polymers as they are transported from WWTP to other ecosystems (Fig. 2 and Sect. 2.1). Indeed, Arcobacter spp. have been found to be prevalent members of the "landfill microbiome" in the USA [51] and have also been detected in sewage [52].

The objective of Lagarde et al. [46] was to examine the growth of a microalga (Chlamydomonas reinhardtii) on plastic particles over time, determine the effect of plastic type on algal growth, and measure particle aggregation. The authors found little effect of plastic (high-density polyethylene [HDPE] or polypropylene [PP]) on algal growth, but contact with polymer particles altered the expression of genes for some sugars used in extracellular polysaccharides. On PP, algal biofilms increased particle aggregation, which was not observed for HDPE. Research has recently been aimed at characterizing the sedimentation rates of microplastics in freshwater and marine environments [26, 35, 36]. Lagarde et al. [46] add to our understanding of microplastic movement by showing that aggregation of plastic particles via biofilm attachment occurs differently among polymer types, which will affect their suspension or deposition. Future studies will benefit from extrapolating this approach to in situ analyses, as well as comparing findings between marine and freshwater environments. For example, the types and sinking rates of algal microplastic aggregates within marine environments are known to be species specific [35], and similar interactions could affect the distribution of microplastics in rivers and lakes. 


\subsection{Potential for Pathogenesis, Toxicant Transfer, and Biodegradation}

\subsubsection{Microplastics as Vectors for Pathogen Transfer and Biotoxins}

Gene sequencing analyses initially highlighted how microplastics may function as vectors for the transport of potential pathogens including Vibrio and Arcobacter spp. $[21,30,45,48,53]$. A high proportion of $16 \mathrm{~S}$ rDNA reads $(24 \%)$ could be attributed to Vibrio spp. detected on PP and, to a lesser extent, on polyethylene (PE) collected at a station in North Atlantic waters [48]. Unfortunately, the widely used bacterial metabarcoding technique based on sequencing fragments of the 16S rRNA gene is limited in its ability to provide the required taxonomic resolution for detecting human pathogens [53]. Using oligotyping of $16 \mathrm{~S}$ rRNA gene data, Schmidt et al. [54] obtained more specific results for taxa within the genus Vibrio indicating the presence of potential pathogens affecting animals including fishes, corals, and bivalves in marine or mixed saline plastic samples. The presence of pathogens on plastics sampled from seawater was also implied by increased abundances of genes involved in type IV and type VI secretion systems [49]. However, genes involved in these systems can be involved not only in virulence and infection [55] but also in conjugation [56] and interbacterial interactions [57] that are important in biofilms [58]. Vibrio spp. were additionally isolated from plastic collected from a Scottish beach [59], but no further characterization of the isolates was performed. Only recently was the presence of Vibrio spp. on marine plastics conclusively confirmed by matrix-assisted laser desorption/ionization time-of-flight mass spectrometry (MALDI-ToF MS) [60]. In their study, Kirstein et al. [60] identified $V$. parahaemolyticus, $V$. fluviales, and $V$. alginolyticus on microplastics from the North Sea. Apart from $V$. alginolyticus, these species were also found on plastics collected in the brackish Baltic Sea. In addition to bacteria, microplastics may transport microbial eukaryotes involved in disease transmission [12]. Potentially harmful algae, including Ostreopsis and Coolia spp., have been discovered on plastic in the Mediterranean Sea [61]. To date, the only in situ evidence for microplastic-associated pathogens in unmanaged freshwaters identified an increase in Campylobacteraceae attached to microplastics sourced from an urban river [45]. Specifically, 16S rRNA gene sequences related to Arcobacter and Pseudomonas spp. were enriched on plastic in comparison with other suspended matter and the surrounding water.

In summary, current evidence indicates an important role of microplastics as vectors for opportunistic animal and human pathogens. Methodological advances are required to reliably detect viable pathogenic species, so that realistic distribution patterns can be obtained and potential sources can be identified. This is particularly relevant with regard to waters used for recreational [13] but also for industrial purposes such as aquaculture. Relative abundances of Aeromonas spp. (a genus harboring fish pathogens) were increased on riverine plastics [45], implying that such species could take advantage of microplastics as vectors. This possibility is reinforced by the presence of Aeromonas salmonicida, causing 
furunculosis in hatcheries, on several plastic types [62]. Recently, 16S rRNA gene sequences affiliated to Tenacibaculum spp. (another genus including fish pathogens) were detected on PET in seawater [42]. Research has only started to shed light on this issue, as well as the ability of polymers to transport biologically produced toxins.

\subsubsection{Biodegradation and Pollutant Transport}

Several reviews of research into plastic biodegradation have been published (e.g., see $[11-13,24,63-65])$. Therefore, only a brief overview of this topic is provided. Plastic biodegradation involves several steps during which the polymer is enzymatically cleaved into oligomers and monomers that can be assimilated by microorganisms [65]. Many microbial taxa can degrade biopolymers ${ }^{2}$ including polyhydroxybutyrate (PHB) and polyhydroxybutyrate-polyhydroxyvalerate (PHBV). The biodegradation rates of biopolymers in freshwater have been found to exceed those in marine environments, and higher rates have also been observed in sewage than within natural freshwaters $[63,66,67]$. Even so, these materials can still persist for considerable periods of time in freshwaters, with a lifespan of $\sim 10$ years having been estimated for PHBV bottles deposited onto lake sediments at a depth of $85 \mathrm{~m} \mathrm{[68].}$

In comparison with biopolymers, traditional plastics (such as PE, PET, and PP) will persist for even longer within aquatic environments (decades or centuries; $[11,63,64])$, with biodegradation typically preceded by abiotic weathering $[24,65]$. Although it has been unclear whether plastisphere members can biodegrade conventional plastics [11, 69, 70], a bacterial strain isolated from sediment near a Japanese bottle recycling facility (Ideonella sakaiensis) was recently found to assimilate PET [18]. The strain was shown to employ two enzymes to degrade PET at a daily rate of $0.13 \mathrm{mg} \mathrm{cm}^{-2}$ when incubated at $30^{\circ} \mathrm{C}$ [18]. This finding implies that other synthetic plastic-degrading taxa are likely to be present within aquatic environments. Indeed, colonization of plastics by potentially hydrocarbonoclastic bacteria has been observed in both marine and freshwater habitats [21, 45, 47-49]. However, due to a lack of research into plastisphere physiology, the long residence times of plastic waste, and the ability of polymers to adsorb polyaromatic hydrocarbons $[11,12]$, the mechanisms underlying recruitment of hydrocarbon degraders on microplastics are unknown. These and other taxa could mediate desorption and/or degradation of several plastic-associated compounds, including additives and diverse pollutants, with implications for the ecological impacts of microplastics. Indeed, Bryant et al. [49] already reported the presence of diverse xenobiotic degradation genes in association with marine plastic debris. Since organic contaminants and metals rapidly partition into biofilms

\footnotetext{
${ }^{2}$ Polymers derived from renewable biomass (as opposed to nonrenewable fossil fuels).
} 
[71, 72], plastisphere communities may alternatively be hypothesized to facilitate transport of pollutants between ecosystems and to biota (Sect. 3.2).

\section{Knowledge Gaps and Research Needs}

\subsection{Sources and Transport Between Habitats}

Processes contributing to microplastic transport differ between freshwater and marine ecosystems (Sect. 2.1). Conditions encountered within WWTP and unmanaged freshwaters also differ from one another. A priority for research involves determining the extent to which plastic-colonizing taxa associated with wastewater and other sources of plastic (such as landfills) are transported downstream along rivers and streams and whether they remain viable and active upon entering marine habitats [12,40]. As part of this work, research is required to characterize the residence times of polymer particles within several environments, including different stages of the wastewater treatment process. Most WWTPs are based on three main treatment stages, although slight differences in their configuration can be found. During primary treatment, large debris fragments are removed by using a $6 \mathrm{~mm}$ (or larger) screen mesh. During secondary treatment, large aeration tanks are used to remove suspended and dissolved organic material and nutrients through microbial activity. Subsequently, flocculates and settling tanks are used to facilitate separation of sewage sludge from the post-processing effluent prior to a potential disinfection step, also known as advanced tertiary treatment. Studies reporting pathways of microplastics through different wastewater treatment stages are only beginning to emerge [73-75], and little is still known about how these stages influence the development of plastisphere microbial communities.

Overall, studies of microplastic movement and associated biofilms should be based on well-established principles of ecosystem and community ecology [39] and are prerequisite to estimating the spatial scales over which plastics are distributed within a watershed. This approach will best inform how plastic-associated microbial communities can be expected to change with movement from freshwater to marine habitats. There is also a need to compare plastisphere communities in managed and natural environments, within several locations along the water column, as well as between pelagic and benthic habitats. Research into plasticassociated biofilms has focused on surface waters (despite the long-term accumulation of microplastics in sediments; [8, 27]), and investigations of benthic plastisphere assemblages have been restricted to marine habitats [21, 47]. In several environments, no information is available on plastic-associated microbial assemblages. For example, no data have yet been published on plastisphere consortia within WWTP, and although the buildup of plastic debris in deep-sea environments has been reported [76], biofilms associated with this debris have not been studied. 
This lack of data limits our ability to predict the ecological consequences and lifetimes of plastic pollution (Sects. 3.2 and 3.3).

\subsection{Interactions with Higher Organisms and the Wider Environment}

Interactions between plastisphere communities and higher organisms have been recommended as a topic for research in marine environments [11, 12], but they also require investigation within freshwaters. Many organisms including fishes, gastropods, and zooplankton (e.g., Daphnia magna) ingest microplastics [2]. Indeed, nanopolystyrene has been found to negatively affect reproduction in $D$. magna, as well as population growth in the primary producer Scenedesmus obliquus [77]. Effects of plastic-sorbed chemicals have been rarely studied, but liver toxicity was observed in Japanese medaka [78]. A significant knowledge gap is the in situ analysis of microplastic present within freshwater organisms. Such analyses will need to consider how plastic-associated biofilms may amend the buoyancy of polymer particles and/or influence organismal behavior (e.g., selective feeding). Additionally, research is needed to investigate the pathogenicity of plasticcolonizing microbial taxa, as well as their ability to produce toxins. Oberbeckmann et al. [12] suggested that microplastics could carry pathogens encountered in the feces of marine organisms, and transport of human fecal bacteria on plastics has also been discussed [13]. There is a particular requirement to determine how this debris affects organisms at low trophic levels, such as invertebrates used for biomonitoring purposes [79, 80]. Impacts of plastisphere assemblages on processes such as nutrient cycling and primary production should also be investigated. Indeed, Bryant et al. [49] reported high densities of chlorophyll $a$ and an increased abundance of nitrogen fixation genes (nifH, nifD, and nifK) on polymers in comparison with other sample types, leading the authors to suggest that plastic particles may constitute autotrophic "hot spots" in seawater.

Further to impacts on the fitness of plastic-ingesting taxa and processes including elemental cycling, interactions between plastisphere assemblages and other organisms may influence the distribution and fate of plastic waste. For example, microplastics may become transported away from surface waters via encapsulation within fecal pellets [81]. Although this topic has not been investigated in freshwater or marine environments, the gut bacteria of mealworms (larvae of Tenebrio molitor Linnaeus) can degrade polystyrene [82], and certain aquatic organisms could harbor microorganisms capable of modifying the surface properties of plastics and/or biodegrading them. Thus, investigating the interactions between plastisphere communities and 
other organisms is closely connected to research into the transport of plastics between habitats (Sect. 3.1) and the environmental lifetime of this debris (Sect. 3.3).

While this chapter focuses on freshwater and marine environments, plastisphere communities may also be of significance to human health. Risks associated with the human ingestion of microscopic plastics have been identified [83], and investigations of this topic could also be approached from a microbiological viewpoint. In particular, the human health implications of putative pathogens within plasticassociated biofilms (Sect. 2.3.1 and [13]) merit further study.

\subsection{In Situ Biodegradability of Plastics and Plastic-Associated Compounds}

The recent evidence for PET assimilation by I. sakaiensis [18] suggests that, although rates of plastic breakdown in the environment are extremely low (Sect. 2.3.2), several novel polymer-degrading taxa are likely to be present within freshwater and marine ecosystems. Identifying such taxa and investigating their ability to biodegrade different plastic types, additives, and polymer-sorbed compounds are of primary importance to understanding the environmental residence times of plastic waste. Research in this area should focus on habitats functioning as sinks for the accumulation of plastic, including sediments [3-5, 27]. To obtain a complete understanding of the biodegradability of different materials and compounds, there is a need to combine laboratory-based experiments with field-based measurements of plastic degradation in both freshwater and marine environments. Moreover, as nanometer-sized plastic particles become released from the parent polymer as a result of weathering [84], their biodegradation behavior will need to be compared with that of larger fragments that may support a comparatively complex biofilm community. Most research into plastic biodegradation has been based on indirect measurements such as mass loss [11], and a key challenge will be to conclusively demonstrate in situ assimilation of carbon from a given plastic type (or plasticassociated compound) [18]. The toxicity of any degradation products, or of compounds released from the polymer, will also require investigation (Sect. 3.2).

\subsection{Analytical and Experimental Advances in Plastisphere Research}

Research into plastisphere assemblages has focused on bacterial communities $[44,45]$. Little is known about plastic-associated microbial eukaryotes in freshwaters, and there is a need for analyses targeting these organisms, not the least as they are known to occur on marine plastics [48, 49]. Several advances have improved the suitability of metabarcoding for analyzing fungi, diatoms, and protists 
Novel experimental developments

\author{
Metabarcoding and 'omics' \\ Analyses of eukaryotic communities \\ (fungi, diatoms, protists)
}

\section{Single-cell activity probing \\ Stable isotope labeling ${ }^{\star}$, BONCAT, FACS + MDA \\ * Combined with e.g. Raman microspectroscopy and/or (nano)SIMS}

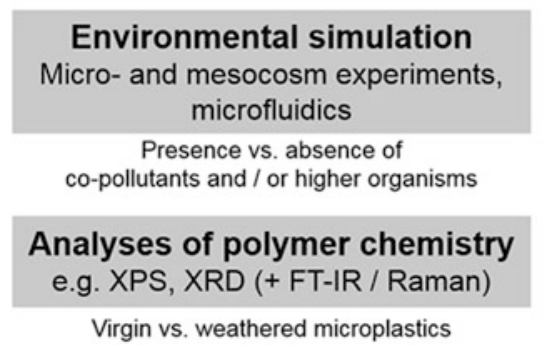

\section{New insights}

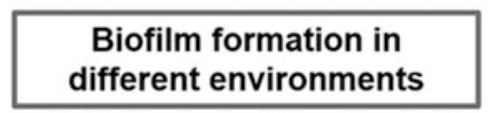

E.g. freshwater, brackish and marine / pelagic and benthic / light and dark / aerobic and anaerobic / eutrophic and oligotrophic

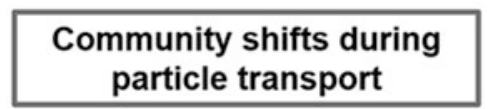

E.g. from WWTP to rivers and marine environments (+ transport from landfill and into lakes)

\section{Plastisphere
physiology and metabolism}

Disease and toxin transfer; biodegradation of plastics, polymer additives and co-pollutants

Fig. 3 Moving beyond initial research into the taxonomy and formation of plastisphere microbial assemblages. As investigations of this topic mature, new types of experiments and analytical tools are anticipated to improve our knowledge of topics including how plastisphere communities develop in several types of habitat, how they are affected by transport from freshwater to marine environments, and the metabolic functions of plastic-colonizing microorganisms

[85-87]. This approach is based on taxonomically informative markers and provides no direct information on metabolic activities. Overcoming this limitation could involve using metagenomics or metatranscriptomics, with the former providing information on metabolic capability [49] and the latter enabling investigations of functional gene expression [20] (Fig. 3). The origin of plastic-colonizing pathogens could be determined by whole genome sequencing followed by genome comparisons or identification of single-nucleotide polymorphism (SNP), approaches widely used in bacterial epidemiology. This would result in important insights into the transfer of pathogens on plastics, provided that suitable databases are available for comparison [88, 89].

Several further developments could enable us to move beyond initial studies of biofilm formation on microplastics (Fig. 3). Stable isotope labeling is increasingly used to characterize microbial activity at the single-cell level, including methods such as heavy water labeling [90] and bioorthogonal noncanonical amino acid tagging (BONCAT) [91]. Heavy water labeling is compatible with Raman spectroscopy and cell sorting using optical tweezers [90], and BONCAT has been combined with fluorescence-activated cell sorting (FACS) [91]. These approaches 
could be followed by multiple displacement amplification (MDA) ${ }^{3}$, enabling identification of taxa that are metabolically active under in situ conditions. Raman spectroscopy has been combined with techniques such as fluorescence in situ hybridization (FISH), which can be used to further investigate the presence and activities of specific microbial taxa [92]. Fourier-transform infrared (FT-IR) spectroscopy has additionally been employed to characterize the chemical composition of biofilms, providing a convenient and low-cost method for analyzing microorganisms adhering to opaque materials [93]. Such methods could be used in conjunction with biological rate measurements (e.g., gas evolution) [44, 49]. This, in turn, could advance our understanding of how plastisphere taxa contribute to disease transmission, nutrient fixation, and pollutant degradation.

Research into microplastic-associated biofilms has relied on samples that were collected in situ or exposed to seawater, with only a small selection of studies involving microcosm experiments under controlled conditions [21, 46, 59]. Mesocosm experiments could be used to bridge the current gap between microcosm studies and field-based research into microplastic-associated biofilms (Fig. 3). Microfluidics is also increasingly used as a tool in microbial ecology and could be employed to obtain insights into microbial-microplastic interactions under selected conditions (e.g., in the presence of fluid flow and chemical gradients) $[94,95]$. To improve our knowledge of the biodegradation of plastics and plasticsorbed pollutants, such approaches could be supplemented by advanced surface analysis techniques. X-ray photoelectron spectroscopy (XPS) and secondary ion mass spectrometry (SIMS) have been used to investigate abiotic weathering of plastics [96-98] and could be valuable for monitoring polymer biodegradation (Fig. 3). Indeed, XPS can detect chemical signatures at the parts-per-thousand (\%o) range [96], and SIMS (including nanoscale SIMS) has been used to trace microbial uptake of ${ }^{13} \mathrm{C}$-labeled substrates in environmental samples [99, 100]. While these techniques are suitable for analyzing organic compounds, X-ray diffraction (XRD) analyses are particularly useful for measurements of inorganic materials, including metals. Although microbial interactions with plastic-associated metals (e.g., metal solubilization or precipitation) have not been previously studied, this could be achieved using XRD (e.g., see Roh et al. [101]).

\section{Concluding Remarks}

Over the past 5 years, several studies have improved our understanding of the taxonomy and potential activities of microbial consortia associated with microplastic particles in the environment. Due to most of these studies focusing on marine ecosystems, there remains a particular lack of information concerning plastisphere assemblages within freshwaters. However, as highlighted in this

\footnotetext{
${ }^{3}$ A method for amplifying very low concentrations of DNA for genomic analysis.
} 
chapter, many of the fundamental processes that underpin the formation and activities of plastic-colonizing biofilms remain poorly understood within both freshwater and marine environments. Establishing an understanding of the implications of microplastic-associated microorganisms for ecosystem and human health, therefore, will require research spanning the entire diversity of environments encountered by these pollutants following their release by industrial and domestic activities.

Acknowledgments We thank Buck Hanson, Toby Samuels, and William Southwell-Wright for their feedback and helpful suggestions.

\section{References}

1. van Sebille E, Wilcox C, Lebreton L et al (2015) A global inventory of small floating plastic debris. Environ Res Lett 10(12):124006. doi:10.1088/1748-9326/10/12/124006

2. Eerkes-Medrano D, Thompson RC, Aldridge DC (2015) Microplastics in freshwater systems: a review of the emerging threats, identification of knowledge gaps and prioritisation of research needs. Water Res 75(15):63-82. doi:10.1016/j.watres.2015.02.012

3. Barnes DKA, Galgani F, Thompson RC et al (2009) Accumulation and fragmentation of plastic debris in global environments. Philos Trans R Soc B 364(1526):1985-1998. doi:10. 1098/rstb.2008.0205

4. Browne MA, Crump P, Niven SJ et al (2011) Accumulation of microplastic on shorelines worldwide: sources and sinks. Environ Sci Technol 45(21):9175-9179. doi:10.1021/ es201811s

5. Corcoran PL (2015) Benthic plastic debris in marine and freshwater environments. Environ Sci: Processes Impacts 17:1363-1369. doi:10.1039/c5em00188a

6. Sadri SS, Thompson RC (2014) On the quantity and composition of floating plastic debris entering and leaving the Tamar Estuary, Southwest England. Mar Poll Bull 81(1):55-60

7. Jambek JR, Geyer R, Wilcox C et al (2015) Plastic waste inputs from land into the ocean. Science 347(6223):768-771

8. van Cauwenberghe L, Devriese L, Galgani F et al (2015) Microplastics in sediments: a review of techniques, occurrence and effects. Mar Environ Res 111:5-17. doi:10.1016/j.marenvres. 2015.06.007

9. Rochman CM, Browne MA, Underwood AJ et al (2016) The ecological impacts of marine debris: unraveling the demonstrated evidence from what is perceived. Ecology 97 (2):302-312. doi:10.1890/14-2070.1

10. Wagner M, Scherer C, Alvarez-Muñoz D et al (2014) Microplastics in freshwater ecosystems: what we know and what we need to know. Environ Sci Eur 26:12. doi:10.1186/s12302014-0012-7

11. Harrison JP, Sapp M, Schratzberger M et al (2011) Interactions between microorganisms and marine microplastics: a call for research. Mar Technol Soc J 45(2):12-20. doi:10.4031/MTSJ. 45.2.2

12. Oberbeckmann S, Löder MGJ, Labrenz M (2015) Marine microplastic-associated biofilms a review. Environ Chem 12(5):551-562. doi:10.1071/EN15069

13. Keswani A, Oliver DM, Gutierrez T et al (2016) Microbial hitchhikers on marine plastic debris: human exposure risks at bathing waters and beach environments. Mar Environ Res 118:10-19. doi:10.1016/j.marenvres.2016.04.006

14. Battin TJ, Besemer K, Bengtsson MM et al (2016) The ecology and biogeochemistry of stream biofilms. Nat Rev Microbiol 14:251-263. doi:10.1038/nrmicro.2016.15 
15. Widder S, Allen RJ, Pfeiffer T et al (2016) Challenges in microbial ecology: building predictive understanding of community function and dynamics. ISME J 10:2557. doi:10. 1038/ismej.2016.45

16. Hoellein TJ, Tank JL, Rosi-Marshall EJ et al (2009) Temporal variation in the substratumspecific rates of $\mathrm{N}$ uptake and metabolism and their contribution at the stream-reach scale. $\mathrm{J} \mathrm{N}$ Am Benthol Soc 28(2):305-318. doi:10.1899/08-073.1

17. Kominoski JS, Hoellein TJ, Kelly JJ et al (2009) Does mixing litter of different qualities alter stream microbial diversity and functioning on individual litter species? Oikos 118 (3):457-463. doi:10.1111/j.1600-0706.2008.17222.x

18. Yoshida S, Hiraga K, Takehana T et al (2016) A bacterium that degrades and assimilates poly (ethylene terephthalate). Science 351(6278):1196-1199. doi:10.1126/science.aad6359

19. O'Toole G, Kaplan HB, Kolter R (2000) Biofilm formation as microbial development. Annu Rev Microbiol 54:49-79. doi:10.1146/annurev.micro.54.1.49

20. Mincer TJ, Zettler ER, Amaral-Zettler LA (2016) Biofilms on plastic debris and their influence on marine nutrient cycling, productivity, and hazardous chemical mobility. In: Takada H, Karapanagioti HK (eds) Hazardous chemicals associated with plastics in the marine environment. Handbook of environmental chemistry. Springer, Heidelberg. doi:10. 1007/698_2016_12

21. Harrison JP, Schratzberger M, Sapp M, Osborn AM (2014) Rapid bacterial colonization of low-density polyethylene microplastics in coastal sediment microcosms. BMC Microbiol 14:232. doi:10.1186/s12866-014-0232-4

22. Fish KE, Osborn AM, Boxall J (2016) Characterising and understanding the impact of microbial biofilms and the extracellular polymeric substance (EPS) matrix in drinking water distribution systems. Environ Sci Water Res Technol 2:614-630. doi:10.1039/ C6EW00039H

23. Carson HS, Nerheim MS, Carroll KA et al (2013) The plastic-associated microorganisms of the North Pacific Gyre. Mar Poll Bull 75(1-2):126-132

24. Gewert B, Plassmann MM, MacLeod M (2015) Pathways for degradation of plastic polymers floating in the marine environment. Environ Sci Process Impacts 17:1513-1521. doi:10.1039/ C5EM00207A

25. Brandon J, Goldstein M, Ohman MD (2016) Long-term aging and degradation of microplastic particles: comparing in situ oceanic and experimental weathering patterns. Mar Poll Bull 110(1):299-308. doi:10.1016/j.marpolbul.2016.06.048

26. Kowalski N, Reichardt AM, Waniek JJ (2016) Sinking rates of microplastics and potential implications of their alteration by physical, biological, and chemical factors. Mar Poll Bull 109(1):310-319. doi:10.1016/j.marpolbul.2016.05.064

27. Corcoran PL, Norris T, Ceccanese T et al (2015) Hidden plastics of Lake Ontario, Canada and their potential preservation in the sediment record. Environ Poll 204:17-25. doi:10.1016/j. envpol.2015.04.009

28. Free CM, Jensen OP, Mason SA et al (2014) High-levels of microplastic pollution in a large, remote, mountain lake. Mar Poll Bull 85(1):156-163. doi:10.1016/j.marpolbul.2014.06.001

29. Oberbeckmann S, Löder MGJ, Gerdts G et al (2014) Spatial and seasonal variation in diversity and structure of microbial biofilms on marine plastics in Northern European waters. FEMS Microbiol Ecol 90(2):478-492. doi:10.1111/1574-6941.12409

30. Amaral-Zettler LA, Zettler ER, Slikas B et al (2015) The biogeography of the plastisphere: implications for policy. Front Ecol Environ 13(10):541-546. doi:10.1890/150017

31. Hullar MA, Kaplan LA, Stahl DA (2006) Recurring seasonal dynamics of microbial communities in stream habitats. Appl Environ Microbiol 72(1):713-722. doi:10.1128/AEM.72.1. 713-722.2006

32. Newbold JD, Mulholland PJ, Elwood JW et al (1982) Organic carbon spiralling in stream ecosystems. Oikos 38(3):266-272. doi:10.2307/3544663 
33. Tank JL, Rosi-Marshall EJ, Griffiths NA et al (2010) A review of allochthonous organic matter dynamics and metabolism in streams. J N Am Benthol Soc 29(1):118-146. doi:10. 1899/08-170.1

34. Webster JR, Benfield EF, Ehrman TP et al (1999) What happens to allochthonous material that falls into streams? A synthesis of new and published information from Coweeta. Freshw Biol 41(4):687-705. doi:10.1046/j.1365-2427.1999.00409.x

35. Long M, Moriceau B, Gallinari M et al (2015) Interactions between microplastics and phytoplankton aggregates: impact on their respective fates. Mar Chem 175:39-46. doi:10. 1016/j.marchem.2015.04.003

36. Nizzetto L, Bussi G, Futter MN et al (2016) A theoretical assessment of microplastic transport in river catchments and their retention by soils and river sediments. Environ Sci Process Impacts 18:1050-1059. doi:10.1039/C6EM00206D

37. Gregory SV, Swanson FJ, McKee WA et al (1991) An ecosystem perspective of riparian zones. Bioscience 41(8):540-551. doi:10.2307/1311607

38. Jones Jr JB, Smock LA (1991) Transport and retention of particulate organic matter in two low-gradient headwater streams. J N Am Benthol Soc 10(2):115-126. doi:10.2307/1467572

39. McCormick AR, Hoellein TJ (2016) Anthropogenic litter is abundant, diverse, and mobile in urban rivers: insights from cross-ecosystem analyses using ecosystem and community ecology tools. Limnol Oceanogr 61:1718-1734. doi:10.1002/lno.10328

40. Osborn AM, Stojkovic S (2014) Marine microbes in the plastic age. Microbiol Aust 35:207-210. doi:10.1071/MA14066

41. Bazire A, Diab F, Jebbar M et al (2007) Influence of high salinity on biofilm formation and benzoate assimilation by Pseudomonas aeruginosa. J Ind Microbiol Biotechnol 34(1):5-8. doi:10.1007/s10295-006-0087-2

42. Oberbeckmann S, Osborn AM, Duhaime MB (2016) Microbes on a bottle: substrate, season and geography influence community composition of microbes colonizing marine plastic debris. PLoS One 11(8):e0159289. doi:10.1371/journal. pone.0159289

43. Dris R, Imhof H, Sanchez W et al (2015) Beyond the ocean: contamination of freshwater ecosystems with (micro-)plastic particles. Environ Chem 12(5):539-550. doi:10.1071/ EN14172

44. Hoellein T, Rojas M, Pink A et al (2014) Anthropogenic litter in urban freshwater ecosystems: distribution and microbial interactions. PLoS One 9(6):e98485. doi:10.1371/journal. pone. 0098485

45. McCormick A, Hoellein J, Mason SA et al (2014) Microplastic is an abundant and distinct microbial habitat in an urban river. Environ Sci Technol 48(20):11863-11871. doi:10.1021/ es503610r

46. Lagarde F, Olivier O, Zanella M et al (2016) Microplastic interactions with freshwater microalgae: hetero-aggregation and changes in plastic density appear strongly dependent on polymer type. Environ Poll 215:331-339. doi:10.1016/j.envpol.2016.05.006

47. De Tender CA, Devriese LI, Haegeman A et al (2015) Bacterial community profiling of plastic litter in the Belgian part of the North Sea. Environ Sci Technol 49(16):9629-9638. doi:10.1021/acs.est.5b01093

48. Zettler ER, Mincer TJ, Amaral-Zettler LA (2013) Life in the "plastisphere": microbial communities on plastic marine debris. Environ Sci Technol 47(13):7137-7146. doi:10. $1021 / \mathrm{es} 401288 \mathrm{x}$

49. Bryant JA, Clemente TM, Viviani DA et al (2016) Diversity and activity of communities inhabiting plastic debris in the North Pacific Gyre. mSystems 1(3):e00024-16. doi:10.1128/ mSystems.00024-16

50. Kalmbach S, Manz W, Bendinger B et al (2000) In situ probing reveals Aquabacterium commune as a widespread and highly abundant bacterial species in drinking water biofilms. Water Res 34(2):575-581. doi:10.1016/S0043-1354(99)00179-7

51. Stamps BW, Lyles CN, Suflita JM et al (2016) Municipal solid waste landfills harbor distinct microbiomes. Front Microbiol 7:534. doi:10.3389/fmicb.2016.00534 
52. Merga JY, Royden A, Pandey AK et al (2014) Arcobacter spp. isolated from untreated domestic effluent. Lett Appl Microbiol 59(1):122-126. doi:10.1111/lam.12256

53. Woo PCY, Lau SKP, Teng JLL et al (2008) Then and now: use of 16S rDNA gene sequencing for bacterial identification and discovery of novel bacteria in clinical microbiology laboratories. Clin Microbiol Infect 14(10):908-934. doi:10.1111/j.1469-0691.2008.02070.x

54. Schmidt VT, Reveillaud J, Zettler E et al (2014) Oligotyping reveals community level habitat selection within the genus Vibrio. Front Microbiol 5:563. doi:10.3389/fmicb.2014.00563

55. Ho BT, Dong TG, Mekalanos JJ (2014) A view to a kill: the bacterial type VI secretion system. Cell Host Microbe 15(1):9-21. doi:10.1016/j.chom.2013.11.008

56. Wallden K, Rivera-Calzada A, Waksman G (2010) Type IV secretion systems: versatility and diversity in function. Cell Microbiol 12(9):1203-1212. doi:10.1111/j.1462-5822.2010. 01499.x

57. Russell AB, Peterson SB, Mougous JD (2014) Type VI secretion system effectors: poisons with a purpose. Nat Rev Microbiol 12(2):137-148. doi:10.1038/nrmicro3185

58. Nadell CD, Drescher K, Foster KR (2016) Spatial structure, cooperation, and competition in biofilms. Nat Rev Microbiol 14:589-600. doi:10.1038/nrmicro.2016.84

59. Quilliam RS, Jamieson J, Oliver DM (2014) Seaweeds and plastic debris can influence the survival of faecal indicator organisms in beach environments. Mar Poll Bull 84 (1-2):201-207. doi:10.1016/j.marpolbul.2014.05.011

60. Kirstein IV, Kirmizi S, Wichels A et al (2016) Dangerous hitchhikers? Evidence for potentially pathogenic Vibrio spp. on microplastic particles. Mar Environ Res 120:1-8. doi:10. 1016/j.marenvres.2016.07.004

61. Masó M, Garcés E, Pagès F et al (2003) Drifting plastic debris as a potential vector for dispersing harmful algal bloom (HAB) species. Sci Mar 67(1):107-111. doi:10.3989/scimar. 2003.67n1107

62. Carballo J, Seoane RM, Nieto TP (2000) Adhesion of Aeromonas salmonicida to materials used in aquaculture. Bull Eur Assoc Fish Pathol 20(2):77-82

63. Müller R-J (2015) Biodegradation behaviour of polymers in liquid environments. In: Bastioli C (ed) Handbook of biodegradable polymers. Rapra Technology Limited, Billingham, pp 33-55

64. Krueger MC, Harms H, Schlosser D (2015) Prospects for microbiological solutions to environmental pollution with plastics. Appl Microbiol Biotechnol 99(21):8857-8874. doi:10.1007/s00253-015-6879-4

65. Lucas N, Bienaime C, Belloy C et al (2008) Polymer biodegradation: mechanisms and estimation techniques - a review. Chemosphere 73(4):429-442. doi:10.1016/j. chemosphere.2008.06.064

66. Ohura T, Aoyagi Y, Takagi K et al (1999) Biodegradation of poly(3-hydroxyalkanoic acids) fibers and isolation of poly(3-hydroxybutyric acid)-degrading microorganisms under aquatic environments. Polym Degrad Stab 63(1):23-29. doi:10.1016/S0141-3910(98)00057-3

67. Manna A, Paul AK (2000) Degradation of microbial polyester poly(3-hydroxybutyrate) in environmental samples and in culture. Biodegradation 11(5):323-329. doi:10.1023/ A:1011162624704

68. Brandl H, Püchner P (1991) Biodegradation of plastic bottles made from 'Biopol' in an aquatic ecosystem under in situ conditions. Biodegradation 2(4):237-243. doi:10.1007/ BF00114555

69. Nauendorf A, Krause S, Bigalke NK et al (2016) Microbial colonization and degradation of polyethylene and biodegradable plastic bags in temperate fine-grained organic-rich marine sediments. Mar Pollut Bull 103(1-2):168-178. doi:10.1016/j.marpolbul.2015.12.024

70. Roy PK, Hakkarainen M, Varma IK et al (2011) Degradable polyethylene: fantasy or reality. Environ Sci Technol 45(10):4217-4227. doi:10.1021/es104042f

71. Headley JV, Gandrass J, Kuballa J et al (1998) Rates of sorption and partitioning of contaminants in river biofilm. Environ Sci Technol 32(24):3968-3973. doi:10.1021/ es9804991 
72. Tien C-J, Chen CS (2013) Patterns of metal accumulation by natural river biofilms during their growth and seasonal succession. Arch Environ Contam Toxicol 64(4):605-616. doi:10. 1007/s00244-012-9856-2

73. Carr SA, Liu J, Tesoro AG (2016) Transport and fate of microplastic particles in wastewater treatment plants. Water Res 91:174-182. doi:10.1016/j.watres.2016.01.002

74. Mason SA, Garneau D, Sutton R et al (2016) Microplastic pollution is widely detected in US municipal wastewater treatment plant effluent. Environ Pollut 218:1045-1054. doi:10.1016/j. envpol.2016.08.056

75. Murphy F, Ewan C, Carbonnier F et al (2016) Wastewater treatment works (WwTW) as a source of microplastics in the aquatic environment. Environ Sci Technol 50(11):5800-5808. doi:10.1021/acs.est.5b05416

76. Woodall LC, Sanchez-Vidal A, Canals M et al (2014) The deep sea is a major sink for microplastic debris. R Soc Open Sci 1:140317. doi:10.1098/rsos.140317

77. Besseling E, Wang B, Lürling M et al (2014) Nanoplastic affects growth of S. obliquus and reproduction of D. magna. Environ Sci Technol 48(20):12336-12343. doi:10.1021/ es503001d

78. Rochman CM, Hoh E, Kurobe $\mathrm{T}$ et al (2013) Ingested plastic transfers hazardous chemicals to fish and induces hepatic stress. Sci Rep 3:3263. doi:10.1038/srep03263

79. Schratzberger M, Gee JM, Rees HL et al (2000) The structure and taxonomic composition of sublittoral meiofauna assemblages as an indicator of the status of marine environments. J Mar Biol Assoc UK 80(6):969-980. doi:10.1017/S0025315400003039

80. Diaz RJ, Solan M, Valente RM (2004) A review of approaches for classifying benthic habitats and evaluating habitat quality. J Environ Manag 73(3):165-181. doi:10.1016/j. jenvman.2004.06.004

81. Cole M, Lindeque PK, Fileman E et al (2016) Microplastics alter the properties and sinking rates of zooplankton faecal pellets. Environ Sci Technol 50(6):3239-3246. doi:10.1021/acs. est.5b05905

82. Yang Y, Yang J, W-M W et al (2015) Biodegradation and mineralization of polystyrene by plastic-eating mealworms: part 2. Role of gut microorganisms. Environ Sci Technol 49 (20):12087-12093. doi:10.1021/acs.est.5b02663

83. Galloway TS (2015) Micro- and nano-plastics and human health. In: Bergmann M, Gutow L, Klages M (eds) Marine anthropogenic litter. Springer, Berlin, pp 343-366. doi:10.1007/9783-319-16510-3_13

84. Lambert S, Wagner M (2016) Formation of microscopic particles during the degradation of different polymers. Chemosphere 161:510-517. doi:10.1016/j.chemosphere.2016.07.042

85. Bokulich NA, Mills DA (2013) Improved selection of internal transcribed spacer-specific primers enables quantitative, ultra-high-throughput profiling of fungal communities. Appl Environ Microbiol 79(8):2519-2526. doi:10.1128/AEM.03870-12

86. Visco JA, Apothéloz-Perret-Gentil L, Cordonier A et al (2015) Environmental monitoring: inferring the diatom index from next-generation sequencing data. Environ Sci Technol 49 (13):7597-7605. doi:10.1021/es506158m

87. Grossmann L, Jensen M, Heider D et al (2016) Protistan community analysis: key findings of a large-scale molecular sampling. ISME J 10:2269-2279. doi:10.1038/ismej.2016.10

88. Didelot X, Bowden R, Wilson DJ et al (2012) Transforming clinical microbiology with bacterial genome sequencing. Nat Rev Genet 13:601-612. doi:10.1038/nrg3226

89. Ruan Z, Feng Y (2016) BacWGSTdb, a database for genotyping and source tracking bacterial pathogens. Nucleic Acids Res 44(D1):D682-D687. doi:10.1093/nar/gkv1004

90. Berry D, Mader E, Lee TK et al (2015) Tracking heavy water $\left(\mathrm{D}_{2} \mathrm{O}\right)$ incorporation for identifying and sorting active microbial cells. Proc Natl Acad Sci U S A 112(2):E194E203. doi:10.1073/pnas.1420406112

91. Hatzenpichler R, Connon SA, Goudeau D et al (2016) Visualizing in situ translational activity for identifying and sorting slow-growing archaeal-bacterial consortia. Proc Natl Acad Sci U S A 113(28):E4069-E4078. doi:10.1073/pnas.1603757113 
92. Wang Y, Huang WE, Cui L et al (2016) Single cell stable isotope probing in microbiology using Raman microspectroscopy. Curr Opin Biotechnol 41:34-42. doi:10.1016/j.copbio. 2016.04.018

93. Ojeda JJ, Romero-González ME, Banwart SA (2009) Analysis of bacteria on steel surfaces using reflectance micro-Fourier transform infrared spectroscopy. Anal Chem 81 (15):6467-6473. doi:10.1021/ac900841c

94. Rusconi R, Garren M, Stocker R (2014) Microfluidics expanding the frontiers of microbial ecology. Annu Rev Biophys 43:65-91. doi:10.1146/annurev-biophys-051013-022916

95. Foulon V, Le Roux F, Lambert C et al (2016) Colonization of polystyrene microparticles by Vibrio crassostreae: light and electron microscopic investigation. Environ Sci Technol 50:10988. doi:10.1021/acs.est.6b02720

96. Briggs D, Brewis D, Dahm R et al (2003) Analysis of the surface chemistry of oxidized polyethylene: comparison of XPS and ToF-SIMS. Surf Interface Anal 35:156-167. doi:10. 1002/sia. 1515

97. Biesinger MC, Corcoran PL, Walzak MJ (2011) Developing ToF-SIMS methods for investigating the degradation of plastic debris on beaches. Surf Interface Anal 43:443-445. doi:10. 1002/sia.3397

98. Jungnickel H, Pund R, Tentschert J et al (2016) Time-of-flight secondary ion mass spectrometry (ToF-SIMS)-based analysis and imaging of polyethylene microplastics formation during sea surf simulation. Sci Total Environ 563-564:261-266. doi:10.1016/j.scitotenv. 2016.04.025

99. Pumphrey GM, Hanson BT, Chandra S et al (2009) Dynamic secondary ion mass spectrometry imaging of microbial populations utilizing ${ }^{13} \mathrm{C}$-labelled substrates in pure culture and in soil. Environ Microbiol 11(1):220-229. doi:10.1111/j.1462-2920.2008.01757.x

100. Eichorst SA, Strasser F, Woyke T et al (2015) Advancements in the application of NanoSIMS and Raman microspectroscopy to investigate the activity of microbial cells in soils. FEMS Microbiol Ecol 91(10):fiv106. doi:10.1093/femsec/fiv106

101. Roh Y, Gao H, Vali H et al (2006) Metal reduction and iron biomineralization by a psychrotolerant Fe(III)-reducing bacterium, Shewanella sp. strain PV-4. Appl Environ Microbiol 72(5):3236-3244. doi:10.1128/AEM.72.5.3236-3244.2006

Open Access This chapter is licensed under the terms of the Creative Commons Attribution 4.0 International License (http://creativecommons.org/licenses/by/4.0/), which permits use, sharing, adaptation, distribution and reproduction in any medium or format, as long as you give appropriate credit to the original author(s) and the source, provide a link to the Creative Commons license and indicate if changes were made.

The images or other third party material in this chapter are included in the chapter's Creative Commons license, unless indicated otherwise in a credit line to the material. If material is not included in the chapter's Creative Commons license and your intended use is not permitted by statutory regulation or exceeds the permitted use, you will need to obtain permission directly from the copyright holder.

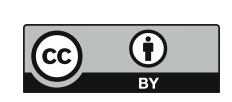

